\title{
TOMÁS DE AQUINO E OS ATRIBUTOS DIVINOS $^{1}$
}

\author{
Lucio Souza Lobo (UFPR) ${ }^{2}$ \\ luciosouzalobo@yahoo.com.br
}

Resumo: Este texto trata de alguns dos principais mecanismos usados por Santo Tomás de Aquino para lidar com os atributos divinos. Decorrem da multiplicidade e complexidade desses atributos uma série de problemas que, a nosso ver, são entendidos pelo Aquinate como passíveis de serem resolvidos unicamente mediante uma correta escolha do instrumento filosófico mais adequado para cada caso. Causa unívoca e causa equívoca, res significata e modus significandi, analogia, via negativa e via por eminência, similitude, axioma do nada, entre outros, são apresentados numa seqüência que julgamos facilitar sua compreensão. Por fim, nosso propósito é, sobretudo, o de apresentar o leitor ao modo de proceder de Santo Tomás quando freqüenta esse tema.

Palavras-chave: atributos divinos, similitude, analogia.

\section{INTRODUÇÃO}

Santo Tomás observa, na Suma Contra os Gentios I, capítulo 3, 1, que "[...] nem toda verdade pode ser descoberta da mesma maneira [...]", e essa observação cabe muito bem ao caso peculiar que é o estudo sobre Deus. Uma boa regra para se conhecer um objeto, qualquer que seja ele, é saber primeiro se ele existe e, após, quais as suas características. Santo Tomás segue essa regra em suas duas Sumas. Para ele, (i) podemos conhecer que Deus seja (exista) e (ii) podemos conhecer os atributos divinos e deles falar.

\footnotetext{
${ }^{1}$ Recebido: 17.11.2010 /Aprovado: 03.07.2011 /Publicado on-line: 07-09-2011.

${ }^{2}$ Lucio Souza Lobo é Professor-adjunto do Departamento de Filosofia da Universidade Federal do Paraná, Curitiba, Brasil.
} 
Com o intuito de mostrar que é possível se chegar a um conhecimento de que Deus existe, Santo Tomás apresenta argumentos em prol desta existência, cuja mais célebre formulação encontra-se nas 'cinco vias' expostas na Suma de Teologia I, q. 2, a. 3. Contudo, como não é objetivo nosso tratar dessa tese tomásica aqui, iremos deixá-la de lado e passaremos ao problema que vai nos ocupar nas páginas seguintes, a saber, como os atributos divinos $\mathrm{e}$ as características divinas podem estar, de uma forma ou de outra, ao alcance do nosso entendimento.

Procurarei mostrar que é da junção e articulação de diversos mecanismos que Santo Tomás extrai a possibilidade de se aplicar nomes a Deus. A meu ver, o Aquinate entende que o problema da aplicação de predicados a Deus não pode ser resolvido mediante um único instrumento filosófico, o que se torna manifesto, por exemplo, na questão 13 da primeira parte da Suma de Teologia. As diferentes questões impostas à predicação divina demandam a aplicação de teses, princípios e distinções diversas; cada caso será um caso. Explicar a aplicação de nomes a Deus deve levar em consideração nosso modo de conhecimento, o fundamento ontológico dos seres a que temos um acesso direto, princípios metafísicos e distinções explicativas. $\mathrm{O}$ que pretendo fazer nas próximas páginas é apresentar um conjunto mínimo dos instrumentos que Santo Tomás usou para defender a possibilidade de um discurso sobre Deus não restrito unicamente à esfera da fé.

\section{OBJETOS DO NOSSO CONHECIMENTO}

Santo Tomás nos diz que, no caso de Deus, não podemos, na nossa atual condição, conhecer a Sua essência. Sobre es- 
te tema a razão humana não alcança um conhecimento perfeito. A essência de Deus permanece inacessível ao entendimento humano enquanto ele se vale de suas próprias forças somente. Mesmo assim, Santo Tomás acredita que se pode atingir um conhecimento relativo (indigente, é verdade, mas certo) acerca da natureza divina:

Nosso conhecimento natural tem sua origem nos sentidos e por isso só pode alcançar até onde possa levar-lhe o sensível. O sensível não pode elevar a inteligência a ponto de ver a essência divina, porque as criaturas sensíveis são efeitos que não se equiparam com o poder de sua causa; por isso não é possível conhecer com seu auxílio todo o poder de Deus nem, portanto, ver sua essência. Não obstante, como são efeitos seus e dele dependem como causa, podem levar-nos a conhecer a existência de Deus e o que necessariamente lhe convém como atributo enquanto é causa primeira de todas as coisas, mas que transcende todos os seus efeitos. Por isso, podemos conhecer sua relação com as criaturas, ou seja, que é causa de todas elas, e a diferença entre as criaturas e ele [...]. (STh I, q. 12, a. 12, resp.)

O homem não deve desistir de obter um conhecimento natural de Deus. Resignar-se perante a transcendência e calarse não é uma atitude digna de um ser racional; ao menos não enquanto não se prove que o discurso é desprovido de sentido. Mas Santo Tomás afirma que tal discurso, resultado de um exame filosófico da natureza divina, possui sim um significado possível e, por isso, legítimo.

A relação entre Criador e criaturas - fundada na Criação, admitida pelo princípio de similitude e expressa pela analogia - nos garante a possibilidade de um discurso significativo. Estamos habilitados a alcançar um conhecimento acerca de Deus a partir do nosso conhecimento das criaturas.

Todo ser que de alguma forma possui existência substancial pode ser disposto ou classificado, segundo Santo 
Tomás, em um destes três conjuntos: (a) Deus, (b) anjos e (c) seres compostos de matéria e forma. Enquanto o conjunto (a) é um composto de um só elemento (e só pode sêlo), os conjuntos (b) e (c) possuem diversos. Outrossim, enquanto os seres dos conjuntos (a) e (b) não são acessíveis diretamente a nós por via da nossa sensibilidade, os seres incluídos no grupo (c) o são. Ora, como Santo Tomás aceita a tese de que todo nosso conhecimento principia pela experiência sensível, um conhecimento acerca de Deus só pode, nesta vida, partir dos seres que contemplamos no mundo que nos rodeia. Os seres em questão estão compreendidos justamente no grupo (c). É a esses seres que nossa atenção deve voltar-se a fim de que possamos alcançar, ainda que indiretamente, algum conhecimento sobre Deus.

Além disso, há outra razão pela qual devemos começar nossa investigação pelos seres compostos de matéria e forma. Santo Tomás defende uma teoria criacionista ${ }^{3}$ segundo a qual tudo o que não é Deus e existe foi criado por Ele. E está envolvido aqui um princípio metafísico que tem implicações diretas sobre a teoria criacionista, a saber, o princípio de que todo efeito guarda algum grau de similitude com sua causa. Assim, por um lado, podemos conhecer a existência de Deus a posteriori pela necessidade que a realidade criada tem de um Causa primeira que explique sua existência, seu movimento, suas perfeições e ordenação, e, por outro, podemos, de um modo imperfeito, conhecer sua natureza a partir da similitude encontrada nas criaturas.

\footnotetext{
${ }^{3}$ Devemos aqui compreender criação em um sentido metafísico e não temporal. Para Santo Tomás, pode-se argumentar filosoficamente que a realidade criada é dependente existencialmente de Deus, que é chamado de Criador, nesse contexto, por ser o responsável pelo esse das criaturas. No entanto, segundo ele, o discurso filosófico não é capaz de provar a criação temporal do mundo, que é, portanto, uma verdade revelada. A esse respeito, ver Wippel (1984).
} 
Pois bem, se o objeto imediato do nosso conhecimento é o dado colhido pela sensibilidade e, além disso, se a nossa sensibilidade só tem acesso direto aos seres compostos de matéria e forma que povoam o mundo à nossa volta e, ainda, se estes seres guardam algum grau de semelhança com o ser que os criou (Deus), então pode-se ver por que Santo Tomás optou por explicar a possibilidade de um conhecimento de Deus via seres compostos de matéria e forma.

Marcado este primeiro ponto, ou seja, que nosso conhecimento de Deus deve partir do exame dos seres compostos de matéria e forma e todos, necessariamente, criados por Ele, podemos nos ocupar do que (e como) os seres inclusos no conjunto (c) nos dizem de Deus.

\section{ASPECTOS ONTOLÓGICOS}

Os seres criados mantêm com Deus uma dupla ligação metafísica. De um lado, Deus é aquele que sustenta todos os seres criados no ser (existência). De outro, nos defrontamos com o princípio metafísico da similitude. Prerrogativa da ação criadora de Deus, a manutenção das criaturas como existentes revela a bondade de Deus, sua vontade de agir e, ainda, algo da dimensão de seu poder. Mais que isso, a criação aponta para aquilo que de mais íntimo há em todo ser criado, a saber, sua completa e inapagável dependência da sempre presente sustentação que Deus oferece. Este elo metafísico já nos fornece algumas informações acerca da natureza divina. Mas ele não parece ser o principal no conjunto da argumentação tomásica que agora abordamos: como podemos conhecer algo acerca de Deus?

Santo Tomás é muito mais incisivo quando lança mão do segundo elo metafísico: a similitudo. Por que isso? A meu 
ver, por se tratar de uma fonte explicativa mais acessível, dada a multiplicidade de seres no mundo, e mais rica porque a variedade de perfeições que podemos perceber é maior. Santo Tomás se refere a ela em diversos textos (cf. SCG I, c. 8 e SCG II, c. 22, 6). Todo efeito guarda uma semelhança, seja proporcional, seja desproporcional, com sua causa. Princípio metafísico que abarca todo ser causado, a similitude é considerada por Santo Tomás como uma consequência necessária da causalidade. Nenhum efeito prescinde de ou possui uma perfeição que não tenha sido dada por sua causa. E isso se baseia mais fundamentalmente no axioma do nada, que se expressa assim: do nada, nada vem. A marca deixada pela causa em seus efeitos revela algo de comum a ambas e, consequentemente, por tratar-se de uma relação de dependência, nos revela algo da causa por intermédio do efeito. Contudo, nem sempre a perfeição recebida pelo efeito é de mesma ordem que a presente na causa. A relação entre as criaturas e Deus é o exemplo máximo desse tipo de caso. Examinemos isso mais detidamente.

\section{CAUSA UNÍVOCA E CAUSA EQUívOCA}

O primeiro ponto a ser considerado na relação ontológica que estabelece a similaridade entre efeito e causa é aquele que distingue dois modos de relação que podem estar envolvidos. Santo Tomás está preocupado em resguardar a transcendência divina. Por isso, ele não se isenta de distinguir entre causas que mantêm proporções ontológicas com seus efeitos e causas que não o fazem. Deus é uma causa que ultrapassa infinitamente todos os seus efeitos. Ele não pode, portanto, ser pensado ou descrito da mesma maneira 
que quando se diz, por exemplo, que um homem é tão "homem" quanto o homem que ele gera. Pai e filho possuem o mesmo grau de humanidade, ainda que um seja causa de outro. O homem gerador de outro homem é tão homem em ato quanto o outro. A forma presente na causa e no efeito é a mesma: a forma humana. É por essa razão que se predica univocamente o pai e o filho quando se os chama de "homem".

$\mathrm{Na}$ relação de causalidade Deus/criaturas, as coisas se dão de maneira diferente. Deus é o que Santo Tomás chama de "causa equívoca", ou seja, uma causa desproporcionada a seu efeito. Ela é desproporcionada a seu efeito porque a maneira de ser da causa é infinitamente superior à maneira de ser do efeito e a perfeição concedida ao efeito encontra-se na causa de modo diferente. Ora, no caso da relação Deus/criaturas, há um bom motivo para isso: como o ser divino é infinitamente perfeito e o ser das criaturas é limitado, estas (efeitos) não podem receber a forma presente em sua causa a não ser na medida em que suas naturezas assim o comportem. Como o ser da causa é ontologicamente superior ao ser do efeito, a forma que ele comunica será recebida de maneira diminuída no efeito. Santo Tomás nos diz que:

[...] os efeitos que são mais fracos que suas causas não podem equivaler a elas, nem pelo nome nem pela significação do nome; deve-se, no entanto, encontrar entre os efeitos e as causas uma certa semelhança, pois é da natureza da ação que o agente produza seu semelhante, cada qual agindo na medida em que está em ato. (SCG I, cap. 29, 2)

Ora, Deus não está em ato da mesma maneira que as criaturas. Ele é ato puro, algo que toda criatura, por definição, não pode ser. A distinção entre "causa unívoca" e "causa 
equívoca" ${ }^{4}$ é, assim, usada por Santo Tomás para garantir que se evite o perigo de, em se estabelecendo uma relação, se equipar a criatura ao criador e se obscurecer a noção da transcendência divina. Mas voltemo-nos, agora, para outra importante distinção.

\section{RES SIGNIFICATA E MODUS SIGNIFICANDI}

Uma característica comum a muitos autores medievais é uma postura de precaução frente à atribuição de nomes a Deus. Dois exemplos que interessaram a Santo Tomás foram o de Maimônides e o do Pseudo-Dionísio. Maimônides rejeitou a real significação dos termos que usamos para designar atributos divinos quando usados como atributos divinos. Já o Pseudo-Dionísio admitiu algum grau de significação a eles, e Santo Tomás o acompanhou nessa posição ${ }^{5}$. É legítimo falar-se de Deus usando certas palavras, afirma Santo Tomás. Em todo caso, para o Aquinate, ainda que se possa predicar algo de Deus, o discurso é insuficiente, o que significa dizer que ele fracassa em alcançar o mesmo nível de significação que o nosso falar usual sobre o mundo comporta. Qual, então, a significação e a validade daquilo que consideramos atributos de Deus, designados pelos chamados "nomes divinos"?

Santo Tomás defende que há significação e validade na utilização de certos termos e põe-se a prová-las através de uma reflexão sobre os limites e a forma da inteligibilidade da nossa linguagem. Em outras palavras, a correta aborda-

\footnotetext{
${ }^{4}$ Não se deve confundir aqui o uso das expressões "causa unívoca" e "causa equívoca", empregados, por exemplo, na Suma Teológica, parte 1, questão 6, artigo 2, com as expressões "termos unívocos”, “termos equívocos" e "termos análogos". Trata-se de causas, no primeiro caso, e de termos, no segundo.

${ }^{5}$ A esse respeito ver Jordan (1983, 161-190).
} 
gem do problema deve examinar alguns pontos do nosso processo cognoscitivo e linguístico. Podemos considerar dois tipos de propriedades nas coisas: essenciais e acidentais. As essenciais, marcando aquilo que a coisa é, não podem ser subtraídas. $\mathrm{O}$ ser perde a sua forma ao perder uma propriedade essencial e, destarte, ele torna-se algo diferente do que era. Ou seja, não mais pertence à espécie original, mas à outra, pois se transformou em outra coisa. Um homem que perca sua racionalidade (propriedade essencial da espécie humana) não pode mais ser considerado um homem.

As propriedades acidentais, diferentemente das essenciais, não comprometem, com sua eventual perda, o ser da coisa. Estar à esquerda ou à direita, ser alto ou baixo, ter estudo ou não, beber vinho ou água são propriedades acidentais porque em nada interferem na natureza humana, por exemplo. Pois bem, Santo Tomás nega a predicação acidental a Deus tendo em vista a Sua imutabilidade. Deus não possui potência passiva e é absolutamente simples, portanto, nada que d'Ele se diga pode implicar em algum tipo de acidente em Sua substância. $\mathrm{O}$ acidente se agrega à substância, o que acarreta uma composição no ser. Como isso não pode ocorrer com um ser absolutamente simples, descarta-se a possibilidade de uma predicação acidental quando tratamos de Deus.

Quanto à predicação essencial, ela também deve ser vista com prudência. Santo Tomás diz que nosso conhecimento tem por base a experiência do mundo sensível. É ao observar a natureza que desenvolvemos nossa linguagem. Olhando para o mundo, o homem descobre sua diversidade e as similaridades presentes nas espécies e nos gêneros; a atenção aos seres individuais revela isso. Em 
princípio, poderia parecer que - com base na similitude entre efeito e causa - poderíamos atribuir a Deus nomes que significassem sua essência (quididade), da mesma maneira como o fazemos com os demais seres. Mas é justamente aqui que Santo Tomás faz a seguinte, e importante, consideração: o grau de perfeição presente nas criaturas não possui medida de comparação com a perfeição divina. Decorre daí que o nosso modo de conferir significação aos predicados que usamos ao nomear as criaturas não pode ser o mesmo que se use para nomear a Deus. Em outras palavras, nosso intelecto compreende as perfeições como elas estão presentes nas criaturas, e isso limita nossa capacidade cognitiva para compreender tais perfeições na medida em que podemos conhecer as criaturas. Se é assim, os nomes que atribuímos a Deus são projetados além de sua original significação. "Bom”, por exemplo, que é enquadrado na categoria acidental da qualidade, passa a ser entendido substancialmente ${ }^{6}$.

$\bigcirc$ que as palavras significam em si mesmas, por outro lado, não sofre com a deficiência ou limitação do nosso modo de pensar, nem o ser ao qual elas se aplicam. Por isso, nelas mesmas, o significado pode ser pertinente a Deus e significá-Lo essencialmente, embora não possamos compreendê-lo completamente. É neste contexto que Santo Tomás entende que os nomes que significam puras perfeições podem ser propriamente ditos de Deus, isto é, com vistas àquilo que eles significam neles mesmos e independentemente de nosso modo de os entender.

Em suma, os nomes significados neles mesmos (ratio

\footnotetext{
${ }^{6}$ Este último período é uma paráfrase de uma elucidativa passagem escrita por Mark D. Jordan em "The names of God and the being of names" que se encontra em Freddoso (1983, 164-165).
} 
propria) são verdadeiramente predicados de Deus (neste caso, res significata) porque realmente o apresentam de alguma maneira. Já quanto ao nosso modo de entendê-los, ou seja, quanto ao modus significandi, tais nomes devem ser negados a Deus.

\section{ANALOGIA}

A posição peculiar no campo da significação que acabei de descrever recebe um nome especial na doutrina tomásica, a saber, analogia. As origens de tal doutrina remetem a Aristóteles. Embora não tenha usado o termo "analogia" com o mesmo significado que será utilizado pelos medievais e pelo próprio Aquinate mais tarde, Aristóteles estabeleceu uma teoria de grande repercussão quanto à significação dos nomes. Em especial, convém notar dois modos de significação: sinonímia e homonímia.

Aristóteles apresenta, no primeiro capítulo do tratado das Categorias (1 a 1-2), as seguintes definições: "[...] chamamos homônimas as coisas às quais somente o nome é comum, enquanto a noção designada por este nome é diversa". E, "[...] por outro lado, sinônimo se diz daquilo que, simultaneamente, possui o mesmo nome e identidade de noção [...]" (1 a 5-6); na língua latina, esses termos serão traduzidos como "equívoco" e "unívoco", respectivamente. Sinonímia ou univocidade consiste na aplicação a seres diferentes de um termo comum que lhes sirva de predicado de uma maneira absolutamente adequada, isto é, a definição daquilo a que o nome comum corresponde é a mesma em todos os casos. "Animal" é um termo que se aplica a homem, cavalo, cão, etc. de modo equivalente, porquanto a definição do termo "animal", quando aplicado a homem, 
cavalo e cão, é sempre igual, muito embora se mantenham as diferenças específicas que dizem respeito a cada um deles, como no homem o fato de ser racional, no cavalo o fato de ser quadrúpede, e assim por diante.

Contrariamente, no caso da homonímia ou equivocidade, a definição do termo que é atribuído a diferentes seres não é a mesma; consequentemente, ainda que o termo (ou a palavra) seja o mesmo, seu significado não o é. Com efeito, nesse caso, quando ouvimos dizer que um banco quebrou, a palavra "banco" pode perfeitamente estar se referindo a um banco de jardim ou a um banco instituição financeira. Há, portanto, para cada caso, uma definição diferente que responde pelo significado de "banco".

Nesse mesmo capítulo do tratado das Categorias, Aristóteles não faz qualquer referência a uma posição intermediária entre sinonímia e homonímia. Contudo, ele irá valer-se de uma posição intermediária justamente em uma de suas teorias mais célebres. Ao reconhecer, na teoria das categorias - que refletem de forma analítica o ser em seus gêneros máximos -, uma unidade real de dependência das categorias acidentais para com a categoria da substância, Aristóteles também se obriga a admitir uma significação diferenciada do termo "ser", quando se aplica aos acidentes e quando se aplica à substância. Para Aristóteles, o ser não se diz sinonimamente das substâncias e dos acidentes porque substâncias e acidentes não são seres. Entretanto, esse caso não se reduz a uma absoluta homonímia. Isto é, há algum tipo de unidade que permanece mesmo com a exclusão da sinonímia.

Santo Tomás acompanha Aristóteles nesse ponto e conclui, também, que ser não é um gênero, pois a ele nada se pode agregar a modo de uma diferença específica. Todo 
ser é realmente ser, o que se deriva do princípio de que 'aquilo que é, é', mas não da mesma maneira. O ser da substância é um ser per se, e o ser dos acidentes é um ser dependente da substância. Assim, o conceito de "ser" não pode ser univocamente aplicado à substância e aos acidentes. Não obstante, reiteramos, "ser" se aplica legitimamente a ambos, pois tudo o que é, seja substância, seja acidente, é ser de algum modo. Essa unidade de significação que se observa não pode ser a da univocidade, pois o modo de ser é diverso e, mesmo assim, há uma unidade. G. Owen (1986, 180-199) a chamará de focal meaning e a interpretará como uma descoberta tardia do próprio Aristóteles. Foi esse sentido focal, segundo Owen, que permitiu a Aristóteles vislumbrar a possibilidade de uma doutrina do ser enquanto ser. O que nos interessa, entretanto, é que ela é a base de uma noção intermediária de significação entre a univocidade e a equivocidade. Ou seja, há um lastro no ser para aquilo que será, no campo da significação, a analogia.

Considerando que "ser" não se aplica univocamente aos acidentes e à substância (no uso técnico atual, nível horizontal ou predicamental), ele, ainda mais, não pode ser aplicado univocamente a seres díspares como Deus e suas criaturas (nível vertical ou transcendental). Deus é infinitamente superior às criaturas e, portanto, não há nem pode haver, segundo o ponto de vista de Santo Tomás, termo que se aplique univocamente a ambos. Com efeito, a transferência dos nomes da criatura ao criador impõe duas grandes dificuldades, como observa Gilson (1997, 122): a primeira é "[...] designar o ato de existir divino por nomes feitos para designar um existir infinitamente diferente [...]" e a segunda é que "[...] os nomes os quais usamos para designar um objeto são solidários da maneira pela qual nós 
concebemos este objeto [...]". Ambos os problemas parecem obstar definitivamente uma predicação unívoca.

O problema, então, é como sustentar a possibilidade de um discurso significativo acerca dos predicados divinos, já que nossa exigência de pretensão de conhecimento parece ser a busca pela univocidade. Será a posição intermediária da analogia realmente capaz de validar um discurso sobre Deus? Segundo Santo Tomás, sim. E aqui iremos nos valer da interpretação de Gilson (1997) novamente. Sob o ponto de vista metafísico, pondera o autor, não há meio termo entre o ser e o não-ser: ou é, ou não é. Diversamente, sob o ponto de vista lógico, pode-se admitir uma predicação intermediária entre o unívoco e o equívoco. Mas, assim, é de se esperar um questionamento do tipo: pode a lógica contradizer a metafísica? Para Santo Tomás, certamente não. Então, como ele escapa a essa aparente incompatibilidade? Pois parece que, ao aplicarmos um nome a algo, fazemos uma escolha entre aplicá-lo univocamente ou equivocamente. Da mesma forma que um ser contingente pode ser ou não ser, pode-se pensar que tal ou qual nome signifique algo ou não.

Valendo-se, respondo, da doutrina dos graus de ser, fundada na teoria criacionista. Nada há entre o ser e o nãoser. Mas há uma hierarquia de seres estruturada pelos diferentes níveis de perfeição compatíveis com a natureza de cada um. Nessa hierarquia, a perfeição se encontra de forma eminente num primeiro e de forma reduzida nos demais. Santo Tomás inspira-se aqui em Platão e sua doutrina da participação. Os seres criados participam de certas perfeições que se encontram em sua plenitude somente em Deus. A participação é o fundamento in re da predicação analógica. Se a analogia é uma propriedade dos nomes e 
dos conceitos comuns, a participação é a interpretação tomásica da estrutura do existente que justifica a utilização da predicação analógica. Em suma, a analogia é a síntese de dois temas: (i) a unidade de ordem por referência a um primeiro e (ii) a doutrina da participação.

A analogia permite determinar a verdade ou a falsidade de afirmações que lancem mão de termos que não são tomados nem unívoca, nem equivocamente. A analogia é um tipo de unidade que permite isso. Mas qual a forma que Santo Tomás propõe para a analogia?

A forma da predicação analógica é apresentada pelo exemplo da saúde (Cf. STh I, q. 13, a. 5, resp.). O animal é saudável, a comida é saudável, a urina é saudável, o remédio é saudável, etc. Mas, embora se digam saudáveis estes últimos, a saúde é uma propriedade em primeiro lugar do animal. Quando se diz que a comida é saudável, a referência de "saúde" remete diretamente à saúde que a comida pode propiciar ao animal; em si mesma, a comida não é nem deixa de ser saudável, pois 'ser saudável' não é um atributo que lhe seja apropriado. Nesse exemplo, Santo Tomás tenta mostrar a convergência dos múltiplos significados de "saudável" frente à saúde do animal. Todos os demais usos do termo "saudável" estão na dependência da noção de saúde que é própria ao animal.

Esse exemplo é didaticamente proveitoso porque é simples, ou seja, de fácil compreensão. Embora seja de natureza extrínseca, pois atributo pertence ao animal somente, ele vale como modelo. A partir dele, pode-se entender a unidade por referência a um primeiro (unidade focal) das categorias acidentais em relação à substância e das criaturas em relação a Deus. Ser é um predicado que se aplica a todos, mas não da mesma maneira, pois o modo de ser de 
cada um e sua intensidade ou grau de ser é diferente. No entanto, há uma unidade que se preserva, fraca, é verdade, mas suficiente para evitar a equivocidade. Essa unidade é garantida não só pelo sentido focal, mas, também, pelo fato de se dar uma predicação intrínseca, ou seja, o termo "ser" pertence de direito a todos os analogados, embora, como o afirme Santo Tomás: "[...] não tenham exatamente o mesmo sentido, como sucede com os unívocos [...]" (STh I, q. 13 , a. 5 , resp.).

\section{VIA NEGATIVA E VIA POR EMINÊNCIA}

A analogia significou, para Santo Tomás, o modo formalmente correto de se falar de Deus. Satisfez aos dois requisitos básicos: de salvaguardar a distância entre Deus e as criaturas e apresentar uma forma de unidade de significação capaz de excluir a pura equivocidade. Entretanto, ainda que a analogia seja o meio, resta-nos buscar o fim, isto é, se dispomos de uma maneira logicamente aceitável de construir proposições acerca de Deus, falta-nos saber que tipo de conteúdo se pode aplicar a Ele.

O conteúdo conceitual do qual dispomos é obtido no mundo que nos cerca, ou seja, uma parcela do criado. Vimos anteriormente que as criaturas possuem ser e perfeições por participação, o que é uma maneira diminuída de receber uma forma. Por isso, reconhecer que há sabedoria em um homem e que há sabedoria em Deus não significa as afirmar como equivalentes. De fato, Santo Tomás (SCG I, 14, 2) nos diz que "[...] a substância divina ultrapassa toda forma que nosso intelecto possa alcançar. Portanto, nós não estamos habilitados a apreender o que ela é". Essa recusa da possibilidade de apreensão da quidi- 
dade divina não é, contudo, a negação de um conhecimento certo sobre Deus. Na sequência da mesma passagem, Santo Tomás escreve: "[...] nós alcançamos um certo conhecimento ao conhecermos o que ele não é. E nós nos aproximamos tanto mais deste conhecimento quanto nós podemos, por meio de nosso intelecto, negar mais coisas de Deus". Santo Tomás aponta a razão disso logo a seguir, "[...] pois conhecemos tanto melhor cada coisa quando alcançamos mais plenamente em que ela difere das demais; com efeito, cada coisa tem um ser próprio, distinto de todos os outros". O que o Aquinate chamou de 'via negativa' é o processo pelo qual descartamos toda maneira de ser que seja incompatível com a natureza divina. Seu valor se encontra não em permitir dizer o que Deus é, mas sim que, ao dizer o que Ele não é, podemos avançar no conhecimento.

Mas de que maneira isso se dá? Nos seres concretos, buscamos o caráter substancial, e, nas formas, a simplicidade. Contudo, os seres substanciais que nos são presentes são compostos e as formas, que são simples, nós não as encontramos substancialmente. Em ambos os casos não partimos de exemplos muito apropriados para que se construa uma noção adequada de Deus. $\mathrm{O}$ intelecto humano precisa capturar as informações provenientes do mundo por via dos sentidos e as depurar, abstraindo o que nelas há de universal e procurando desvendar os seus princípios. Os predicados que aplicamos a Deus são conseguidos desta maneira.

Observa-se que as criaturas do mundo possuem características que nós adjetivamos como boas ou más. Dentre as que consideramos boas, há um grupo que podemos utilizar para falar de Deus. E falamos de um grupo porque ele não 
esgota todas as boas qualidades possíveis de serem encontradas nas criaturas. Por exemplo, que um tubarão seja rápido para abocanhar suas presas expõe uma qualidade sua, a saber, a rapidez ou velocidade no espaço, que não é o tipo de perfeição que se possa aplicar a Deus; à exceção de casos metafóricos, é claro. Mas a bondade e a inteligência, sim. O grupo de predicados é, portanto, restrito.

Mas isso ainda não é tudo. Há predicados que se aplicam a Deus não por significarem diretamente algo de positivo, mas por negarem de Deus uma imperfeição ou limitação. Trata-se dos predicados negativos: a unidade e a eternidade, por exemplo. Tais predicados são ditos negativos por se formarem a partir da negação da composição em Deus. Deus é uma substância inteiramente simples. A fim de $\mathrm{O}$ nomear, valemo-nos de variados termos, pois, como nossa maneira de conhecer as coisas está limitada pela nossa natureza, que é finita, não podemos nos apropriar de toda a riqueza da perfeição divina mediante um único conceito. E Santo Tomás complementa essa tese observando que "[...] todos esses nomes significam a substância divina e se aplicam a Deus substancialmente, mas não conseguem expressá-lo com perfeição [...]". E segue dizendo: “[...] estes termos significam a Deus segundo o conhece nosso entendimento e, posto que nosso entendimento o conhece por meio das criaturas, segue-se que só o conhece na medida em que estas o representam [...]" (STh I, q. 13, a. 2). Ora, as criaturas são uma multiplicidade. Elas possuem perfeições em pequenos quinhões; pode-se ser justo, inteligente e bom, mas não se pode ser totalmente justo, totalmente inteligente e totalmente bom. O conjunto dos diferentes atributos divinos é a maneira pelo homem encontrada para, de alguma forma, entender o que é Deus em sua plenitude. É 
por esse motivo que nos valemos de uma multiplicidade de predicados. Mas, ao usá-los, precisamos reconhecer a absoluta transcendência do ser divino. Deus não é somente justo, mas infinitamente justo; Deus não é somente sábio, mas infinitamente sábio; Deus não é somente bom, mas infinitamente bom, e assim por diante. É claro que não podemos compreender a infinitude de qualquer dos atributos divinos, mas podemos entender que, no que diz respeito a Deus, todo predicado deve ser elevado ao seu máximo grau ou, em outras palavras, à sua eminência.

O procedimento que nos fornece o grupo de predicados que, ao usarmos para nomear a Deus, nada mais fazem do que excluir imperfeições é denominado via negativa. E o modo através do qual procuramos salientar a excelência e infinitude dos atributos em Deus denominamos via por eminência.

Abstract: This paper describes some of the key mechanisms used by Aquinas to deal with the divine attributes. Arising from the multiplicity and complexity of these attributes a number of problems which, in our view, are understood by Aquinas as likely to be settled only through a correct choice of the most appropriate philosophical instrument for each case. Univocal cause and equivocal cause, res significata and modus significandi, analogy, negative way and way of eminence, similarity, axiom of nowhere, among others, are presented in a sequence that we consider easier to understand. Finally, our purpose is mainly to introduce the reader to Aquinas's modus of proceeding about this topic.

Key-words: divine attributes, similarity, analogy.

\section{REFERÊNCIAS}

ARISTOTE. La Métaphysique. Paris: Vrin, 1948.

FREDDOSO, A. The existence and nature of God. Notre Dame: Indiana, 1983. 
GILSON, E. Le Thomisme. 6. ed. Paris: Vrin, 1997.

JORDAN, M. D. The names of God and the being of names. In: FREDDOSO, A. J. (Org.). The existence and nature of God. Notre Dame: undp, 1983. p. 161-190.

OWEN, G. E. L. Logic and Metaphysics in some earlier works of Aristotle. In: NUSSBAUM, M. Logic, Science and Dialectic. Ithaca: Cornell University Press, 1986. p. 180-99. THOMAS d'AQUIN. Somme contre les gentils. 4 vols. Paris: Flammarion, 1999.

1994.

- Summa theologiae. Madrid: Editorial Católica, WIPPEL, J. Thomas Aquinas on the possibility of eternal creation. In: . Metaphysical themes in Thomas Aquinas. Washington: The Catholic University of America Press, 1984.

. Metaphysical themes in Thomas Aquinas. Washington: The Catholic University of America Press, 1984.

. The metaphysical thought of Thomas Aquinas: from finite being to uncreated being. Washington: CUA Press, 2000. 